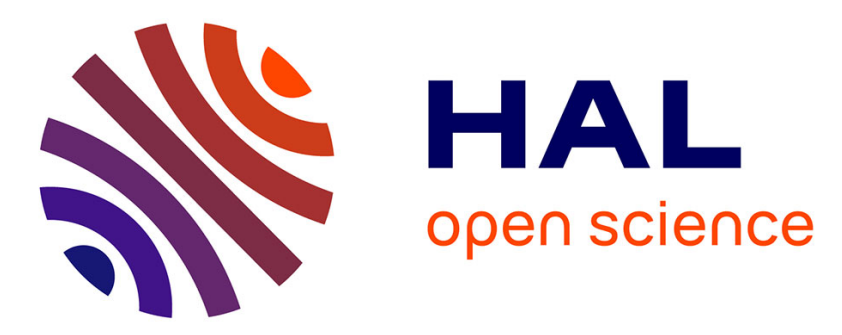

\title{
Probing magnetic interactions in columnar phases of a paramagnetic gold dithiolene complex
}

Romain Perochon, Patrick Davidson, Stéphan Rouziere, Franck Camerel, Lidia Piekara-Sady, Thierry Guizouarn, Marc Fourmigué

\section{To cite this version:}

Romain Perochon, Patrick Davidson, Stéphan Rouziere, Franck Camerel, Lidia Piekara-Sady, et al.. Probing magnetic interactions in columnar phases of a paramagnetic gold dithiolene complex. Journal of Materials Chemistry, 2011, 21, pp.1416-1422. 10.1039/c0jm02171g · hal-00601702

\section{HAL Id: hal-00601702 https://hal.science/hal-00601702}

Submitted on 15 Jul 2013

HAL is a multi-disciplinary open access archive for the deposit and dissemination of scientific research documents, whether they are published or not. The documents may come from teaching and research institutions in France or abroad, or from public or private research centers.
L'archive ouverte pluridisciplinaire HAL, est destinée au dépôt et à la diffusion de documents scientifiques de niveau recherche, publiés ou non, émanant des établissements d'enseignement et de recherche français ou étrangers, des laboratoires publics ou privés. 


\title{
Probing magnetic interactions in columnar phases of a paramagnetic gold dithiolene complex $\dagger+$
}

\author{
Romain Perochon, ${ }^{a}$ Patrick Davidson, ${ }^{b}$ Stéphan Rouzière, ${ }^{b}$ Franck Camerel, ${ }^{\star a}$ Lidia Piekara-Sady, ${ }^{c}$ \\ Thierry Guizouarn ${ }^{a}$ and Marc Fourmigué ${ }^{* a}$
}

\author{
Received 7th July 2010, Accepted 24th August 2010 \\ DOI: 10.1039/c0jm02171g
}

\begin{abstract}
A novel radical gold dithiolene complex exhibits a hexagonal columnar mesophase, as confirmed by optical microscopy, DSC analysis and X-ray diffraction. The extent of delocalization of the spin density in such a complex was analyzed by EPR. Temperature dependent magnetization measurements reveal that the global magnetic moment is remarkably affected at the liquid-crystalline phase transition with a marked hysteresis signature, rare behavior among the few described paramagnetic discotic phases. In addition, these molecules were found to strongly aggregate in solution into one-dimensional fibers with a mean diameter of $60 \mathrm{~nm}$ extending over micrometres, leading to the formation of gel-like structures. These fibers are stable and can be isolated on surfaces. The gelation of the system can also be detected by temperature-dependent magnetic measurements.
\end{abstract}

\section{Introduction}

The development of molecular spin systems with liquid-crystalline properties is particularly interesting in the fields of magnetism and data storage through the possibility offered for modifying the magnetic properties at the phase transitions or for modulating the thermotropic properties with external magnetic fields. While magneto-responsive nematic or smectic thermotropic phases have been the focus of great attention in recent years, ${ }^{1,2}$ only a few discotic systems have been reported to date which involve radical species, either localized on a nitroxide species appended to a discotic triphenylene, ${ }^{3}$ centered on the carbon atom of triarylmethyl radicals ${ }^{4}$ or delocalized in the phthalocyanine rings of radical $(\mathrm{PcLi})^{\cdot}$ or $\left(\mathrm{Pc}_{2} \mathrm{Lu}\right)^{\cdot}$ molecules., The objective of incorporating molecular radicals into discotic phases toward the realization of magneto-responsive columnar phases bears many prospects since the anisotropy of electrical conductivity in these columnar phases can also be used in molecular electronics as one-dimensional conductors in field effect transistors, light-emitting diodes or photovoltaic devices. ${ }^{7}$ Furthermore, discotic molecules can induce the gelation of solvents, leading to the formation of nano-structured objects. ${ }^{8}$ With paramagnetic discotic molecules, the formation of magnetic gels can be therefore anticipated, together with the introduction of switchable magnetic behavior within such nano-

${ }^{a}$ Sciences Chimiques de Rennes, Université Rennes 1, UMR CNRS 6226, Campus de Beaulieu, 35042 Rennes, France.E-mail: franck.camerel@, univ-rennes1.fr; marc.fourmigue@univ-rennes1.fr

${ }^{b}$ Laboratoire de Physique de Solides, Université Paris-Sud, UMR CNRS 8502, Bât. 510, 91405 Orsay, France

'Institute of Molecular Physics, Polish Academy of Science, M. Smoluchowskiego 17, 60-179 Poznań, Poland

$\dagger$ This paper is part of a Journal of Materials Chemistry themed issue in celebration of the 70th birthday of Professor Fred Wudl.

\$ Electronic supplementary information (ESI) available: UV-vis-NIR spectrum, cyclic voltammogram, TGA curve of $\left[\mathrm{Au}\left(\mathrm{OC}_{12}\right)_{8}\right]$ and X-ray diffractogram of a gel of $\left[\mathrm{Au}\left(\mathrm{OC}_{12}\right)_{8}\right]$ in dodecane. See DOI: $10.1039 / \mathrm{c} 0 \mathrm{jm} 02171 \mathrm{~g}$ segregated architectures. Gels sensitive to magnetic fields are of interest as "smart" materials and have potential applications in sensors, controlled delivery systems, separation systems, and artificial muscles. ${ }^{9}$ Up to now, however, magnetic gel formation relies on the incorporation of magnetic nanoparticles into gel matrices but not on the direct use of magnetic gelators.

As the possible observation of magnetic effects in such thermotropic or gelated phases would be based on subtle modifications of intermolecular magnetic interactions within the condensed phases, we envisioned paramagnetic discotic molecules endowed with a delocalized spin density, possibly allowing for sizeable magnetic interactions within the stacks. Paramagnetic square-planar metal-dithiolene complexes are particularly attractive in that respect since the spin density is known to be strongly delocalized on the two dithiolene ligands with a distribution between the metal centre and the dithiolene ligands which depends on the metal and the substituents on the $\mathrm{C}_{2} \mathrm{~S}_{2}$ fragments. ${ }^{10,11}$ Calamitic dithiolene complexes bearing two long alkyl chains were reported to afford nematic or smectic phases ${ }^{12}$ and only discotic nickel complexes with eight alkyl chains (Scheme 1) described by Ohta et al. were found to organize into
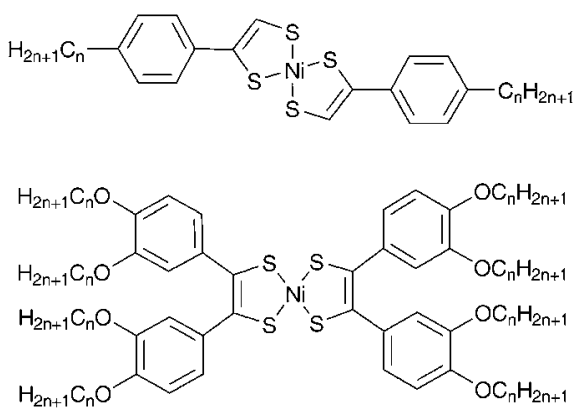

Scheme 1 Examples of reported, diamagnetic, calamitic (top) and discotic (bottom) dithiolene complexes giving rise to thermotropic liquid crystal phases. 
columnar hexagonal phases. ${ }^{13}$ However, all reported thermotropic dithiolene complexes described so far are neutral nickel, palladium or platinum complexes $\left[\mathrm{M}(\text { dithiolene })_{2}\right]^{0}$, and accordingly characterized with a low spin $(S=0)$ state. The radical species which could be of interest are then salts of the $\left[\mathrm{M}(\text { dithiolene })_{2}\right]^{-\cdot}$ radical anions.

Gold dithiolene complexes provide in that respect a very attractive alternative. Indeed, the $\mathrm{d}^{8} \mathrm{Au}(\mathrm{III})$ monoanionic $\left.[\mathrm{Au} \text { (dithiolene })_{2}\right]^{-}$complexes are known to oxidize to the neutral, air-stable radical species $\left[\mathrm{Au}(\text { dithiolene })_{2}\right]^{0} \cdot{ }^{14}$ These complexes are characterized by an extensive delocalization of the spin density on the dithiolene ligands. ${ }^{15,16}$ Their solid state structure often reveals strong intermolecular interactions between radical species, within dyads, ${ }^{17}$ alternated spin chains, ${ }^{18}$ regular stacks with semiconducting ${ }^{19}$ or metallic behaviour. ${ }^{20}$ We have also recently shown that such gold dithiolene complexes, when substituted with bulky ${ }^{21}$ or long linear alkyl chains, ${ }^{22}$ adopt solid state structures closely related to those of the corresponding diamagnetic nickel complexes. As a consequence, we postulated that the gold complex analogues of known discotic nickel complexes could afford neutral and radical complexes with a delocalized spin density able to form original magnetoresponsive thermotropic phases and gels, as demonstrated below.

\section{Experimental}

$3,3^{\prime}, 4,4^{\prime}$-Tetradodecyloxybenzil was prepared as previously described. ${ }^{13}$ Elemental analyses were performed at the CNRS Service de Microanalyse, Gif sur Yvette, France. UV-Vis-NIR spectra were recorded on a Cary 5 spectrophotometer in $\mathrm{CH}_{2} \mathrm{Cl}_{2}$. Cyclic voltammetry was carried out on a $1.5 \times 10^{-3} \mathrm{M}$ solution in $\mathrm{CH}_{2} \mathrm{Cl}_{2}$ (anhydrous grade) containing $0.2 \mathrm{M} n-\mathrm{Bu}_{4} \mathrm{NPF}_{6}$ as supporting electrolyte. Voltammograms were recorded at $0.1 \mathrm{~V} \mathrm{~s}^{-1}$ on a platinum disk electrode $\left(1 \mathrm{~mm}^{2}\right)$. Potentials were measured versus saturated calomel electrode (SCE).

$\left[\mathrm{Au}\left(\mathrm{OC}_{12}\right)_{8}\right]$. A mixture of $3,3^{\prime}, 4,4^{\prime}$-tetradodecyloxybenzil (500 $\mathrm{mg}, 0.53 \mathrm{mmol}$ ) and phosphorus pentasulfide $(352 \mathrm{mg}, 1.6 \mathrm{mmol})$ in 1,3-dimethyl-2-imidazolidinone ( $5 \mathrm{~mL}$ ) was warmed to $110^{\circ} \mathrm{C}$ for $2 \mathrm{~h}$ under argon atmosphere. The reaction mixture was cooled to $60^{\circ} \mathrm{C}$ and a solution of $\mathrm{KAuCl}_{4}(95 \mathrm{mg}, 0.25 \mathrm{mmol})$ in water $(1 \mathrm{~mL})$ was added to the reaction mixture, which was then stirred at $90{ }^{\circ} \mathrm{C}$ for $2 \mathrm{~h}$ in the air. To the resulting mixture was added ethanol and the precipitate was filtered off, washed with ethanol and dried under vacuum. The purification was carried out by chromatography on silica gel, eluting with petroleum ether/ $\mathrm{CH}_{2} \mathrm{Cl}_{2}(7: 3)$ to afford a dark green solid (188 mg, $\left.35 \%\right)$. UV-vis-NIR $\left(\mathrm{CH}_{2} \mathrm{Cl}_{2}\right) \lambda_{\max }: 1612 \mathrm{~nm}\left(\varepsilon=27800 \mathrm{M}^{-1} \mathrm{~cm}^{-1}\right)$. Anal. Calcd for $\mathrm{C}_{124} \mathrm{H}_{212} \mathrm{AuO}_{8} \mathrm{~S}_{4}\left(\mathrm{MW}=2156.27 \mathrm{~g} \mathrm{~mol}^{-1}\right)$ : C, 69.07; H, 9.91. Found: C, 69.12; H, 10.09\%.

The optical textures of thin samples held between a glass slide and a coverslip were observed by polarizing light microscopy, using an Olympus BX 51 microscope equipped with an Olympus Camedia digital camera. The samples were placed in a Mettler FP2 heating stage interfaced to a computer via a homemade electronic controller. Textures were grown by slowly cooling the preparation from the isotropic phase into the mesophase at a rate of $0.1{ }^{\circ} \mathrm{C} \mathrm{min}{ }^{-1}$.

Differential scanning calorimetry (DSC) was performed on a Perkin-Elmer DSC-7 instrument. The samples were examined at a scanning rate of $10 \mathrm{~K} \mathrm{~min}^{-1}$ by applying two heating and one cooling cycles. The apparatus was calibrated with indium $\left(156.6{ }^{\circ} \mathrm{C}\right)$.

X-Ray scattering experiments were performed using a FR591 Bruker AXS rotating anode X-ray generator operated at $50 \mathrm{kV}$ and $50 \mathrm{~mA}$ with monochromatic $\mathrm{Cu}-\mathrm{K} \alpha$ radiation $(\lambda=1.541 \AA)$ and point collimation. The samples were held in Lindemann glass capillaries ( $1 \mathrm{~mm}$ diameter) and heated with a variabletemperature oven. The patterns were collected with a Mar345 Image-Plate detector (Marresearch, Norderstedt, Germany).

The magnetic susceptibility measurements were obtained with the use of a Quantum Design SQUID magnetometer MPMS$\mathrm{XL}$. This magnetometer works between 1.8 and $370 \mathrm{~K}$ for dc applied fields ranging from -7 to $7 \mathrm{~T}$. Solid state magnetic susceptibility measurements were performed on $34 \mathrm{mg}$ of $\left[\mathrm{Au}\left(\mathrm{OC}_{12}\right)_{8}\right]$ powder inserted inside a SQUID gelatine capsule (sample size: $5 \times 5 \times 7 \mathrm{~mm}$ ). The magnetic data were corrected for the sample holder and diamagnetic contributions. Magnetic susceptibility measurements on the $\left[\mathrm{Au}\left(\mathrm{OC}_{12}\right)_{8}\right] /$ dodecane gel $(C=23 \mathrm{mM})$ and on the pure dodecane solution were performed directly inside a EPR quartz tube of $2.5 \mathrm{~mm}$ diameter (height of solution $=2 \mathrm{~cm}$ ).

EPR spectra were obtained either on a X-band Bruker EMX8/2.7 spectrometer in Rennes or on a Radiopan SE/X spectrometer equipped with liquid nitrogen cooling system in Poznan. Simulations were performed with Bruker WinEPR Symphonia.

\section{Results and discussion}

The synthesis of radical gold dithiolene complexes is often based on the chemical or electrochemical oxidation of the parent diamagnetic, $\mathrm{d}^{8}$ monoanionic complexes. ${ }^{14-20}$ However, we have recently found that the sulfuration method used for the direct preparation of neutral low-spin alkyl- or aryl-substituted nickel complexes $^{23}$ could be successfully improved and extended to the preparation of neutral radical gold complexes by using (i) $\mathrm{P}_{4} \mathrm{~S}_{10}$ in dimethylimidazolidinone (DMI), instead of dioxane and (ii) $\mathrm{KAuCl}_{4}$ instead of $\mathrm{NiCl}_{2}$ (Scheme 2). ${ }^{21,22}$

Following this procedure, $\left[\mathrm{Au}\left(\mathrm{OC}_{12}\right)_{8}\right]$ complex was prepared from 3,3',4,4'-tetradodecyloxybenzil in 35\% yield, and the corresponding nickel complex was isolated in $79 \%$ yield, a strong improvement compared to the yields observed in dioxane (Au: $10 \%$, Ni: $56 \%$ ). The complex was purified by chromatography on silica gel to give a dark green solid, soluble in dichloromethane, toluene, chloroform and THF. Electrochemical properties of $\left[\mathrm{Au}\left(\mathrm{OC}_{12}\right)_{8}\right]$ were investigated by cyclic voltammetry in $\mathrm{CH}_{2} \mathrm{Cl}_{2}$. The neutral complex exhibits two reversible redox processes centered at 0.213 and $0.716 \mathrm{~V}$ ( $v s$. SCE), corresponding to the formation of the monoanionic $\left[\mathrm{Au}\left(\mathrm{OC}_{12}\right)_{8}\right]^{-}$and the

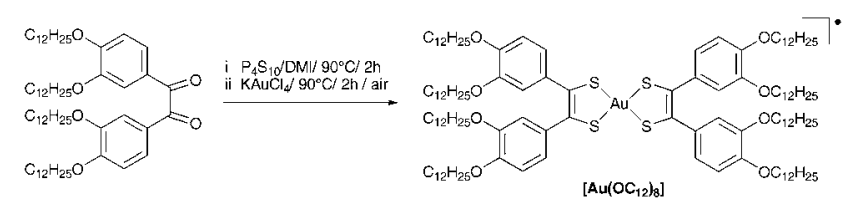

Scheme 2 Synthetic route for the preparation of the neutral radical gold complex $\left[\mathrm{Au}\left(\mathrm{OC}_{12}\right)_{8}\right]$. 
Table 1 Electro- and photochemical properties for various radical gold dithiolene complexes (potentials in $\mathrm{V} v s . \mathrm{SCE}_{2} \mathrm{CH}_{2} \mathrm{Cl}_{2}$ with $0.2 \mathrm{M} \mathrm{Bu}_{4} \mathrm{NPF}_{6}$ at $100 \mathrm{mV} \mathrm{s}^{-1}$ )

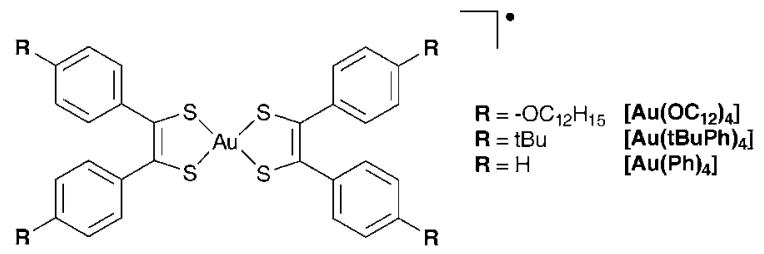

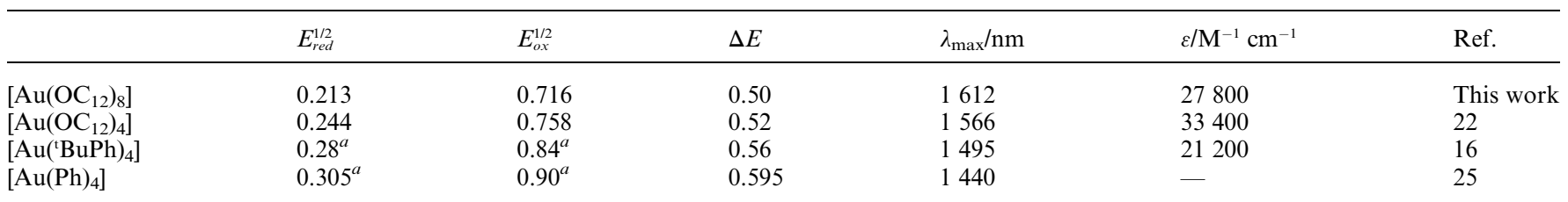

${ }^{a}$ For comparison purposes, values reported $v s . \mathrm{Fc}^{+} / \mathrm{Fc}$ were calculated $v s$. SCE by adding $0.39 \mathrm{~V}$.

monocationic $\left[\mathrm{Au}\left(\mathrm{OC}_{12}\right)_{8}\right]^{+}$species, respectively (Fig. $\left.\mathrm{S} 1 \dagger\right)$. By comparison with less substituted analogous radical gold dithiolene complexes (Table 1), two trends emerge for $\left[\mathrm{Au}\left(\mathrm{OC}_{12}\right)_{8}\right]$ : (i) a notable cathodic shift and (ii) a smaller electrochemical gap, as indicated here from the potential difference $\Delta E=E_{o x}^{1 / 2}-E_{r e d}^{1 / 2}$. Both features can be attributed to the presence of the additional electron-donating alkoxy substituents on each phenyl ring. This reduced electrochemical gap is also associated with a reduced optical gap for these radical species. Indeed, as shown in Table 1, the NIR absorption band, characteristic of square planar metalbis(dithiolene) complexes, ${ }^{24}$ is observed in $\left[\mathrm{Au}\left(\mathrm{OC}_{12}\right)_{8}\right]$ at much lower energy $\left(\lambda_{\max }>1.6 \mu \mathrm{m}\right)$ than in the other complexes (Fig. S2 $\dagger$ ), a consequence of the introduction of additional electron-rich meta alkoxy substituents.

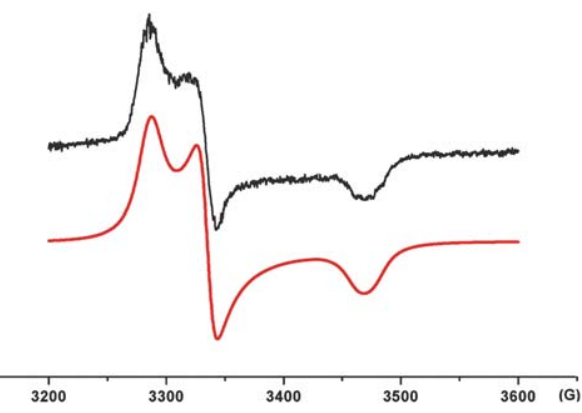

Fig. 1 EPR spectrum of $\left[\mathrm{Au}\left(\mathrm{OC}_{12}\right)_{8}\right]$ in frozen $\mathrm{CH}_{2} \mathrm{Cl}_{2}$ at $77 \mathrm{~K}$. The red line represents the simulation with the parameters reported in Table 2 using the line shape function Lorentzian/Gaussian $=0.5$.

Table 2 Frozen solution EPR characteristics $\left(77 \mathrm{~K}, \mathrm{CH}_{2} \mathrm{Cl}_{2}\right)$ of the radical gold complexes

\begin{tabular}{lllllll}
\hline Complex & $g_{\min }$ & $g_{\text {int }}$ & $g_{\max }$ & $g_{\max }-g_{\min }$ & $10^{-4} \mid A_{0} / \mathrm{cm}^{-1}$ & Ref. \\
\hline$\left[\mathrm{Au}\left(\mathrm{OC}_{12}\right)_{8}\right]$ & 1.948 & 2.027 & 2.056 & 0.108 & $<5$ & This work \\
{$\left[\mathrm{Au}\left(\mathrm{OC}_{12}\right)_{4}\right]$} & 1.950 & 2.026 & 2.058 & 0.108 & $<5$ & 22 \\
{$\left[\mathrm{Au}\left({ }^{\mathrm{B} B P h}\right)_{4}\right]$} & 1.944 & 2.030 & 2.065 & 0.121 & 6.6 & 16 \\
{$\left[\mathrm{Au}(\mathrm{Ph})_{4}\right]_{1}$} & 1.936 & 2.029 & 2.064 & 0.128 & - & 25 \\
{$\left[\mathrm{Au}(\mathrm{mnt})_{2}\right]$} & 1.928 & 2.039 & 2.075 & 0.147 & 7.7 & 16 \\
\hline
\end{tabular}

This extensive delocalization is also confirmed by EPR spectroscopy. The X-band EPR spectrum of $\left[\mathrm{Au}\left(\mathrm{OC}_{12}\right)_{8}\right]$ in frozen $\mathrm{CH}_{2} \mathrm{Cl}_{2}$ solution (Fig. 1) displays an anisotropic signal around $g \approx 2$ that is typical of an $S=1 / 2$ system with rhombic $g$ factors, but without hyperfine splitting from the ${ }^{197} \mathrm{Au}$ nucleus $(I=3 / 2$, $100 \%$ abundance), at variance with the unsubstituted or tertbutyl substituted gold complexes for which a hyperfine structure was observed. Furthermore, the anisotropy of the $g$ tensor, evaluated from the difference $g_{\max }-g_{\min }$ (Table 2) is clearly much smaller in $\left[\mathrm{Au}\left(\mathrm{OC}_{12}\right)_{8}\right]$ or $\left[\mathrm{Au}\left(\mathrm{OC}_{12}\right)_{4}\right]$ than in $[\mathrm{Au}-$ $\left.\left({ }^{\mathrm{t}} \mathrm{BuPh}\right)_{4}\right]$, the unsubstituted complex $\left[\mathrm{Au}(\mathrm{Ph})_{4}\right]$ or $\left[\mathrm{Au}(\mathrm{mnt})_{2}\right]^{\cdot}$, confirming an even smaller spin localization on the gold atom. This localization has been evaluated to be already less than $1 \%$ on $\mathrm{Au}(6 \mathrm{~s})$ and $7 \%$ on $\mathrm{Au}(\mathrm{d})$ for $\left[\mathrm{Au}\left({ }^{\mathrm{t}} \mathrm{BuPh}\right)_{4}\right],{ }^{16}$ and is therefore expected to be even smaller here in $\left[\mathrm{Au}\left(\mathrm{OC}_{12}\right)_{8}\right]$.

All molecular features clearly point to a highly delocalized radical species on the $\left[\mathrm{Au}\left(\mathrm{OC}_{12}\right)_{8}\right]$ molecule, with essentially no metal contribution. This point is extremely important to obtain magnetic effects in the solid state, mesophase or gel, since the required intermolecular interactions would be more limited if the spin density was strongly localized on a single atom at the center of the molecule or complex. In systems where the spin density is strongly delocalized over the whole molecule, the spin/magnetic

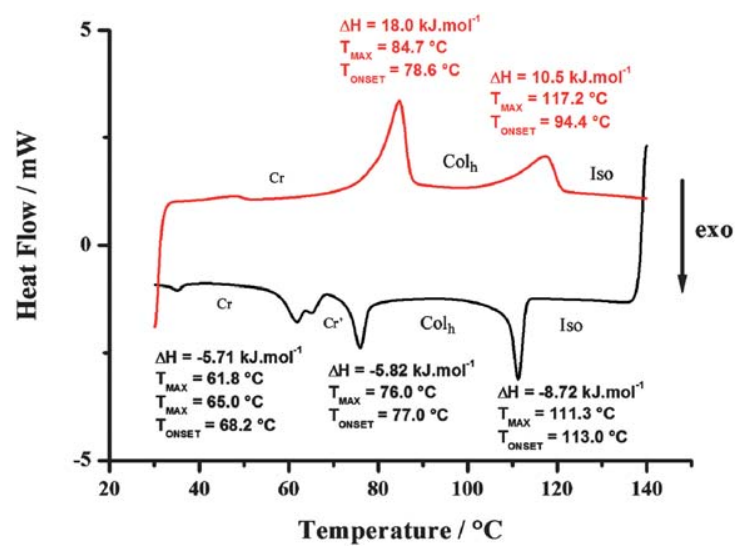

Fig. 2 DSC traces of $\left[\mathrm{Au}\left(\mathrm{OC}_{12}\right)_{8}\right]$ compound. Red: second heating curve, black: first cooling curve. 
interactions are expected to be extremely sensitive to the variation of the local environment around the molecules.

The thermal behavior of the $\left[\mathrm{Au}\left(\mathrm{OC}_{12}\right)_{8}\right]$ complex was investigated by a combination of polarizing optical microscopy (POM), thermogravimetric measurements (TGA) and differential scanning calorimetry (DSC). TGA measurements (Fig. S3†) have revealed that the complex is stable up to $150{ }^{\circ} \mathrm{C}(0.15 \%$ weight lost). DSC heating curves (Fig. 2) displayed two transitions centered at $85^{\circ} \mathrm{C}$ and $117{ }^{\circ} \mathrm{C}$ whereas the DSC cooling curves showed three transitions centered at 111,76 and $65^{\circ} \mathrm{C}$.

POM observations performed above $117^{\circ} \mathrm{C}$ revealed that the material is in an isotropic fluid state. Upon cooling, the material entered a fluid birefringent mesomorphic state and a pseudo-fan shaped texture, typical of columnar mesophases, readily developed (Fig. 3a). The transitions at 76 and $65{ }^{\circ} \mathrm{C}$ were likely attributed to a mesophase/crystal transition and a crystal/crystal transition, respectively, since the texture observed by POM is not fluid any more. The transition detected at $85^{\circ} \mathrm{C}$ on the heating curves is thus attributed to a crystal/mesophase transition. The first DSC heating curve displays an additional strong endothermic transition centered at $72{ }^{\circ} \mathrm{C}$, attributed to some internal rearrangements. These attributions were confirmed by temperature-dependent X-ray diffraction experiments (Fig. 3b). The $\mathrm{X}$-ray diffraction patterns obtained below $85^{\circ} \mathrm{C}$ on heating and $76{ }^{\circ} \mathrm{C}$ on cooling are all characteristic of crystalline phases with the presence of sharp reflections over the whole $2 \theta$ range explored. The XRD diffractograms recorded between 85 and $117{ }^{\circ} \mathrm{C}$ on heating or between 111 and $76^{\circ} \mathrm{C}$ on cooling are identical, and show several sharp and intense small-angle reflections with reciprocal spacings in the ratios $1: \sqrt{ } 3: \sqrt{ } 4: \sqrt{ } 7: \sqrt{ } 9: \sqrt{ } 12$. These six small-angle peaks are most readily assigned as the (10), (11), (20), (21), (30) and (22) reflections of a hexagonal 2D lattice with a parameter $a=33.90 \AA$ (at $T=100{ }^{\circ} \mathrm{C}$ ). The presence of high order reflections indicates that the columnar structure is very well defined while the sharpness of the reflections proves that the columnar order extends over very large distances, in agreement with the POM photograph (Fig. 3a). In the wide angle region, two broad halos centered at $4.5 \AA$ (A) and at $3.6 \AA$ (B) are also observed. These scattering signals can be respectively assigned to the liquid-like order of the aliphatic chains in a molten state and to molecular stacking within the columns.

A simplified standard geometrical treatment confirmed this value of the stacking periodicity $h$ which is related to the
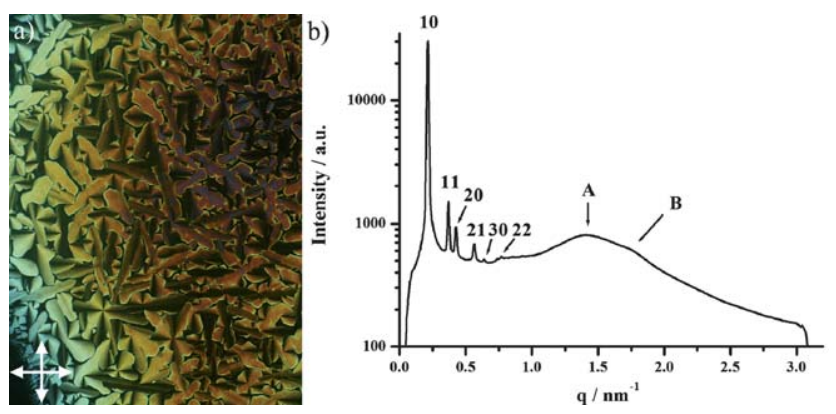

Fig. 3 a) $\left[\mathrm{Au}\left(\mathrm{OC}_{12}\right)_{8}\right]$ observed by optical microscopy at $100^{\circ} \mathrm{C}$ between crossed polarizers (symbolized by the cross in the corner of the picture); b) X-ray diffractogram of the $\mathrm{Col}_{\mathrm{h}}$ phase of $\left[\mathrm{Au}\left(\mathrm{OC}_{12}\right)_{8}\right]$, recorded at $T=$ $100{ }^{\circ} \mathrm{C}$ columnar cross-section $S_{c o l}$ through the relation $h S_{c o l}=Z V_{m}$, where $Z$ is the number of molecules within a columnar stratum (disc) $h$-thick and $V_{m}$ is the molecular volume defined by $V_{m}=$ $(M / 0.6022)(M=$ molecular weight $){ }^{26}$ With one molecule per plateau $(Z=1)$, the stacking periodicity thus found is $3.59 \AA$ in excellent agreement with the value derived from the wide-angle diffuse halo. This value indicates that each slide forming the column is formed by one $\left[\mathrm{Au}\left(\mathrm{OC}_{12}\right)_{8}\right]$ molecule. A mutual rotation of $90^{\circ}$ likely occurs between two consecutive molecules to optimize molecular packing within the mesophase. Rotation of a molecule with respect to the adjacent one inside the column may give rise to better space filling and organization of the pendant phenyl fragments carrying the alkoxy chains (Fig. 4).

This process allows a better arrangement of the chains around the central core of the columns and thus prevents the steric mismatch that could otherwise occur between the preferred corecore $(3.6 \AA)$ and chain-chain $(4.5 \AA)$ distances. The length of the molecule $(L)$ was estimated to be around $45 \AA$ and indicates that the columns are partially interdigitated in the $2 \mathrm{D}$ hexagonal plane $(L>a)$.

Note that the temperature range for the discotic mesophase of $\left[\mathrm{Au}\left(\mathrm{OC}_{12}\right)_{8}\right], 85-117{ }^{\circ} \mathrm{C}$ upon heating, compares with that reported by Ohta for the analogous, closed-shell nickel complex [Ni( $\left.\left(\mathrm{OC}_{12}\right)_{8}\right]: 72-108{ }^{\circ} \mathrm{C}$, with comparable hexagonal 2D lattices, with $a=33.90 \AA$ (at $T=100^{\circ} \mathrm{C}$ ) and $35.6 \AA$ (at $T=80^{\circ} \mathrm{C}$ ) in the gold and nickel complexes respectively. Therefore, the para- or diamagnetic nature of the complexes does not markedly affect their thermotropic behavior. On the other hand, we will see below how the magnetic behavior of the gold complex is actually modified at the crystal/liquid crystal transition.

Below room temperature, the magnetic behavior of $\left[\mathrm{Au}\left(\mathrm{OC}_{12}\right)_{8}\right]$ was deduced from the temperature dependence of the magnetic susceptibility measured with a SQUID magnetometer at $5 \mathrm{kG}$. In the crystalline phase, the decrease of $\chi T$ with decreasing temperature indicates the presence of antiferromagnetic interactions (Fig. 5).

The best fit was obtained within the frame of a uniform spin chain model while other models implying the opening of a spin

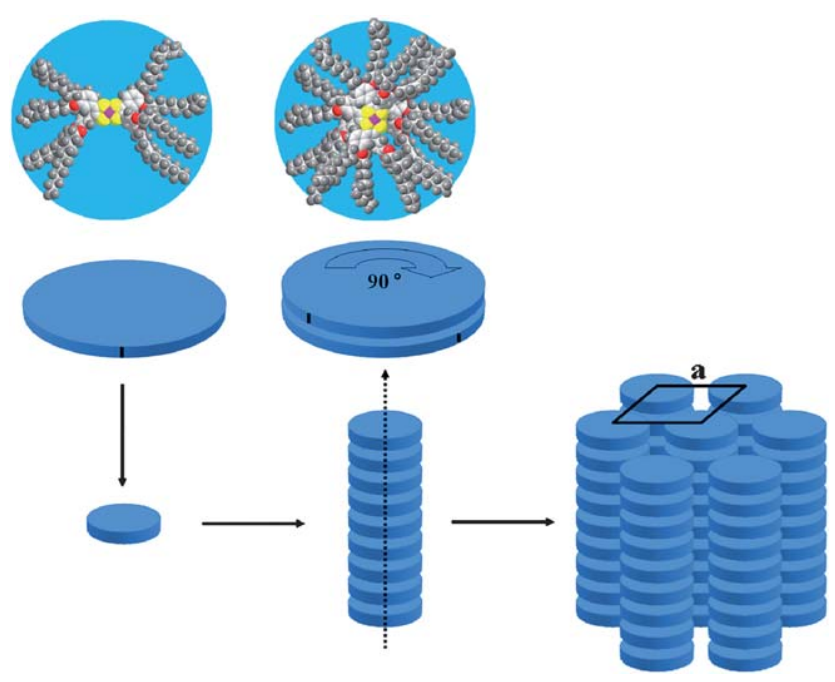

Fig. 4 Suggested molecular organisation based on X-ray data of the $\left[\mathrm{Au}\left(\mathrm{OC}_{12}\right)_{8}\right]$ complexes inside the hexagonal columnar mesophase. 


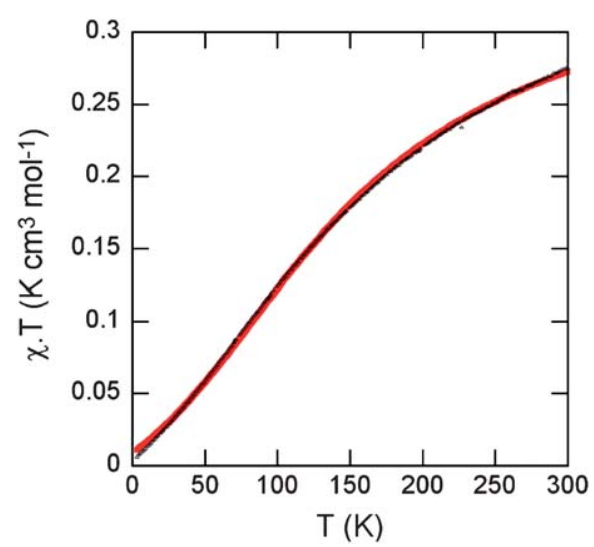

Fig. 5 Temperature dependence of the $\chi T$ product The red line is a fit to the uniform spin chain model (see text).

gap (singlet-triplet, alternated spin chain) were not satisfactory. The following equation was used:

$$
\chi=\rho \frac{N g^{2} \beta^{2}}{k T}+(1-\rho) \chi_{B F}
$$

where $\rho$ is the fraction of Curie-type defects and $\chi_{B F}$ the analytical expression for a Bonner-Fisher mode ${ }^{27,28}$ with the associated Hamiltonian which reads as $H=-J \sum_{i=1}^{n-1} S_{i} S_{i+1}$. The best fit gave $\rho=2.2 \%$ and $J / k=-190.2(6) \mathrm{K}\left(132 \mathrm{~cm}^{-1}\right)$. This behavior contrasts strongly with that of the less substituted complex $\left[\mathrm{Au}\left(\mathrm{OC}_{12}\right)_{4}\right]$ where the X-ray crystal structure and the magnetic behavior indicated unambiguously a strong dimerization within the stacks. ${ }^{22}$ Thus, the introduction of additional carbons chains in the meta position of the phenyl rings destabilizes the formation of dimers and favors the formation of regular chains with uniform antiferromagnetic interactions. The large $J$ value indicates strong intermolecular interactions, in line with a face-to-face stacking of the radical complexes in the crystalline state, with a favorable overlap between the dithiolene moieties.

The evolution of the magnetization at higher temperatures, around the crystal/mesophase transition, was also evaluated in

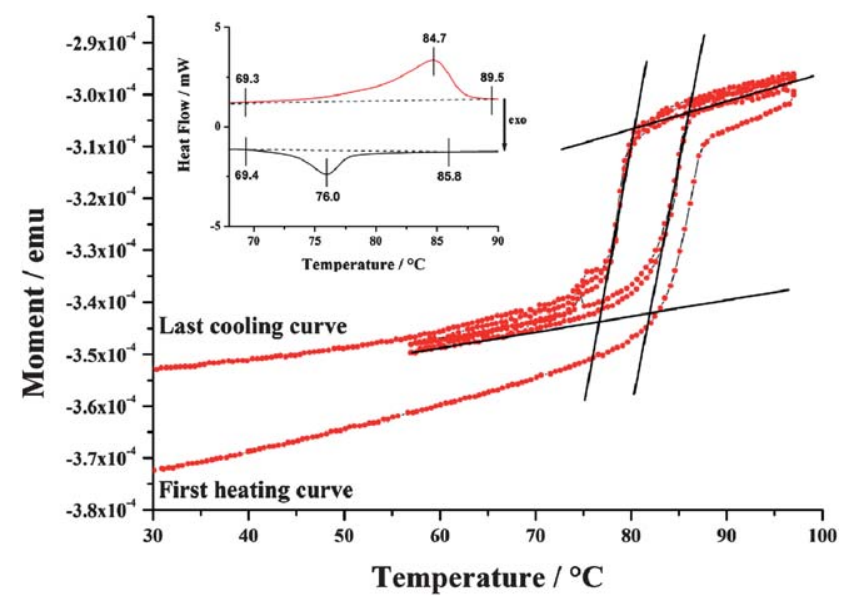

Fig. 6 Temperature dependence of the long moment during heating and cooling cycles around the crystal/mesophase transition at a rate of $10 \mathrm{~K}$ $\mathrm{min}^{-1}$ (insert: DSC traces of $\left[\mathrm{Au}\left(\mathrm{OC}_{12}\right)_{8}\right]$ around the crystal/mesophase transition (second heating curve (upper) and first cooling curve (lower)). the range $27-97^{\circ} \mathrm{C}$ (Fig. 6). On the second and third heating curves, the magnetic moment monotonously increases from $57^{\circ} \mathrm{C}$ to $69{ }^{\circ} \mathrm{C}$. From this temperature, which corresponds to the beginning of the thermal phase transition, up to $89{ }^{\circ} \mathrm{C}$, the magnetization drastically increases with the temperature.

This evolution indicates that the antiferromagnetic interactions present within the stacks in the crystalline state are notably decreased above the crystal/mesophase transition. Above $89^{\circ} \mathrm{C}$, at the end of the transition, the long moment value stabilizes and increases slowly again with temperature. An inflection point is clearly observed around $84-85^{\circ} \mathrm{C}$, which corresponds to the maximum of the peak detected on the DSC heating curve (see insert). On cooling from the mesophase, a drastic decrease of the long moment starts at $85^{\circ} \mathrm{C}$ and an inflection point is detected at lower temperature $\left(78{ }^{\circ} \mathrm{C}\right)$, reflecting the supercooling effect observed on the DSC curves. This behavior is reversible and can be repeated several times so that a clear and well-defined magnetic hysteresis appears around the crystal/mesophase transition. The difference in the magnetization values observed on the first heating curve indicates thermal rearrangements of the complex during the first heating run, as already observed by DSC. The transition from the mesophase to the isotropic liquid could not been explored because of the temperature limitations of the setup. Nevertheless, these results confirm that magnetic measurements can be efficiently used to probe phase transitions in radical liquid-crystalline phases. With such high spin delocalization complexes, the order of magnitude of the magnetic interactions $(|J| / k \approx 200 \mathrm{~K})$ compares with the temperature of the crystal-to-liquid crystal phase transition $(\approx 350 \mathrm{~K})$. Therefore, a sizeable decrease of the $J$ value at the transition leads to an increase of total magnetic moment, reflecting the perturbation to crystalline order of the radical species when entering into the columnar liquid crystal phase. Note that such reversible local perturbations of the intermolecular interactions at the crystal/ mesophase transition were also probed by luminescence measurements in anthanide containing LC systems. ${ }^{29}$

This paramagnetic neutral radical complex $\left[\mathrm{Au}\left(\mathrm{OC}_{12}\right)_{8}\right]$ is also soluble in hot linear alkanes $\left(\mathrm{C}_{6}-\mathrm{C}_{12}\right)$. Upon cooling, the formation of a fluffy precipitate is observed. At high concentrations $(\sim 20 \mathrm{mM})$, this precipitate can trap the solvent and

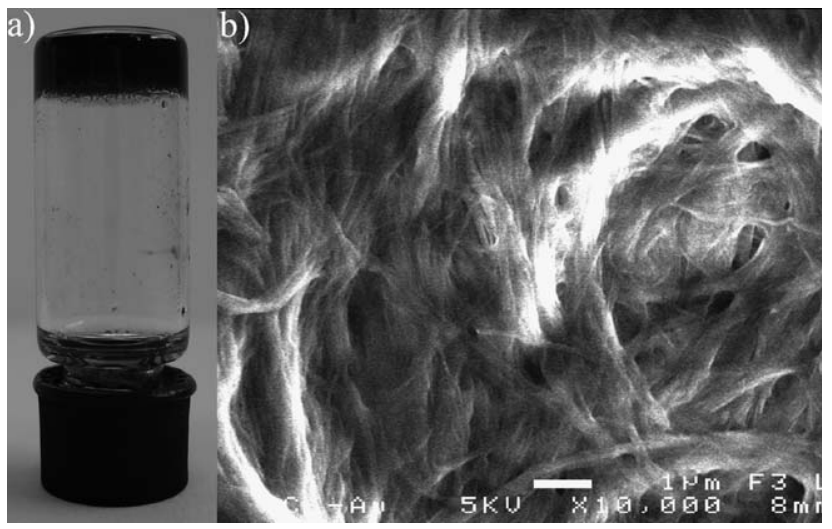

Fig. 7 a) Dark-green gel obtained with $\left[\mathrm{Au}\left(\mathrm{OC}_{12}\right)_{8}\right]$ in dodecane $(23$ $\mathrm{mM})$; b) SEM image of an aerogel gel of compound $\left[\mathrm{Au}\left(\mathrm{OC}_{12}\right)_{8}\right]$ in hexane $(23 \mathrm{mM})$ deposited on silicon wafer showing an interconnected network of fibers. 


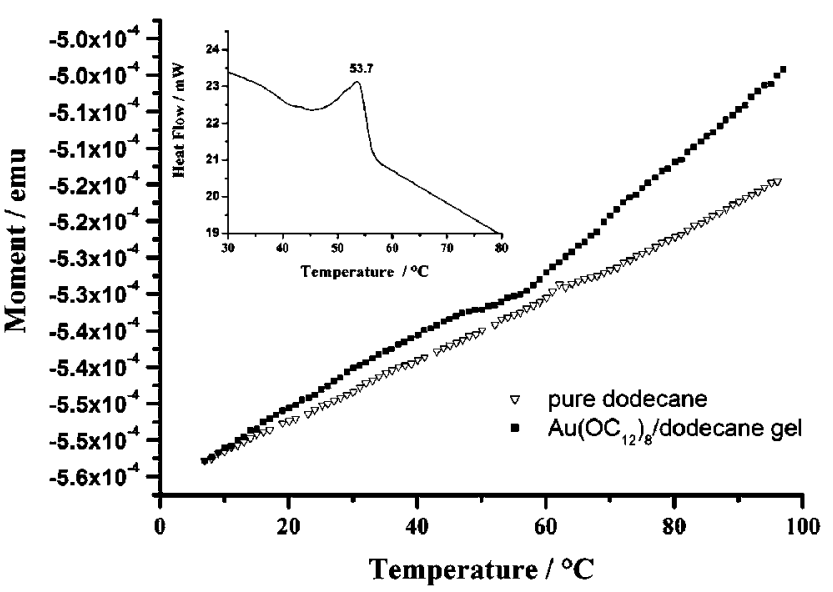

Fig. 8 Evolution of the long moment as a function of the temperature in pure dodecane and in a dodecane gel of compound $\left[\mathrm{Au}\left(\mathrm{OC}_{12}\right)_{8}\right](\mathrm{C}=23$ $\mathrm{mM}$ ) (insert: DSC heating curve of the same gel showing the gel to sol transition).

forms fragile gels (Fig. 7a). Images obtained from aerogels of compound $\left[\mathrm{Au}\left(\mathrm{OC}_{12}\right)_{8}\right]$ in hexane or dodecane by SEM experiments reveal the presence of a 3D network of interlocked thin fibers with diameter of $\sim 60 \mathrm{~nm}$ extending over several micrometres (Fig. 7b).

It is likely that the formation of a 3D network of interlocked fiber-like aggregates is responsible for the gelation of the linear alkanes. The width of the fibers is large compared to the dimensions of the molecule. Therefore, the observed fibers probably correspond to bundles of smaller elongated molecular assemblies. X-Ray diffraction experiments performed with the gels reveal a structure reminiscent of the one observed in the pure solid (Fig. $\mathrm{S} 4 \dagger$ ). The X-ray patterns display several reflections which can be indexed in a 2D-hexagonal lattice with a parameter $a$ of $38.1 \AA$. Comparison with the liquid crystal phase structure ( $a=33.90 \AA$ A) shows that the insertion of solvent molecules inside the fiber structure leads to an increase of the lattice parameter. These data are in line with a gel formation arising from the hierarchical self-assembly of the $\left[\mathrm{Au}\left(\mathrm{OC}_{12}\right)_{8}\right]$ molecules into onedimensional substructures (columns) in solution which further aggregate into a 2D hexagonal lattice to form flexible fibers.

Temperature-dependent magnetic susceptibility measurements were also performed on gels around the gel/sol transition. With only pure dodecane, for comparison, the magnetic moment increases monotonously from 7 to $97{ }^{\circ} \mathrm{C}$ in an almost linear fashion (Fig. 8). In contrast, the curve measured with a dodecane gel of $\left[\mathrm{Au}\left(\mathrm{OC}_{12}\right)_{8}\right]$ displays a clear slope change around $54{ }^{\circ} \mathrm{C}$. This behavior is related to the solubilization/dispersion of the fibers and an increase of the number of weakly interacting radicals. DSC and POM observations confirm a gel-to-sol transition at $54{ }^{\circ} \mathrm{C}$, which corresponds to the solubilisation/dispersion of the fibers in the solvent (insert in Fig. 8).

\section{Conclusions}

The described gold dithiolene complex carrying long carbon chains exhibits radical metallomesogen character and organizes into columnar phases over a large temperature range. This amphiphilic molecule can also gel solvents through the formation of elongated nanostructured fibers, with an internal structure reminiscent of that observed in the solid state and in the mesophase. These results coupled to magnetic measurements highlight the strong tendency of the square planar gold-dithiolene complexes to stack into columns in the pure solid and in solution with the formation of regular chains with uniform antiferromagnetic interactions. EPR, electrochemical and photophysical measurements demonstrate that introduction of additional meta alkoxy substituents affords an extensive spin delocalization over the whole molecule, a favorable situation when one wants to obtain a high sensitivity of magnetic interactions to external stimuli. As a consequence, magnetic measurements performed at the liquid crystal/crystal phase transition revealed indeed marked reversible hysteretic effects, a very original feature which may find applications in data storage or as magnetic sensors.

\section{Acknowledgements}

Financial support from the Région Bretagne through a $\mathrm{PhD}$ grant (to R. P.) is gratefully acknowledged. We thank Dr F. Artzner and C. Mériadec (Rennes) for providing access to the $\mathrm{X}$-ray facilities.

\section{Notes and references}

1 (a) S. Nakatsuji, Adv. Mater., 2001, 13, 1719; (b) S. Nakatsuji, M. Mizumoto, H. Ikemoto, H. Akutsu and J. Yamada, Eur. J. Org. Chem., 2002, 1869; (c) S. Nakatsuji, H. Ikemoto, H. Akutsu, J. Yamada and A. Mori, J. Org. Chem., 2003, 68, 1708; (d) M. Fujino, T. Amano, H. Akutsu, J. Yamada and S. Nakatsuji, Chem. Commun., 2004, 2310; (e) H. Kinoshita, M. Hata, A. S. Achalkumar, C. V. Yelamaggad, H. Akutsu, J. Yamada and S. Nakatsuji, Tetrahedron Lett., 2005, 46, 6701; (f) S. Nakatsuji, M. Fujino, S. Hasegawa, H. Akutsu, J. Yamada, V. S. Gurman and A. Kh. Vorobiev, J. Org. Chem., 2007, 72, 2021.

2 (a) R. Tamura, Y. Uchida and N. Ikuma, J. Mater. Chem., 2008, 18, 2872; (b) N. Ikuma, R. Tamura, S. Shimono, N. Kawame, O. Tamada, N. Sakai, J. Yamauchi and Y. Yamamoto, Angew. Chem., Int. Ed., 2004, 43, 3677; (c) R. Tamura, Nitroxides: Applications in Chemistry, Biomedicine, and Materials Science, ed. Likhtenstein, G. I.; Yamauchi, J.; Nakatsuji, S.; Smirnov A. I.; Tamura, R., Wiley-VCH, Weinheim, 2008, ch. 9; (d) N. Ikuma, R. Tamura, S. Shimono, Y. Uchida, K. Masaki, J. Yamauchi, Y. Aoki and H. Nohira, Adv. Mater., 2006, 18, 477 .

3 C. V. Yelamaggad, A. S. Achalkumar, D. S. Shankar Rao, M. Nobusawa, H. Akutsu, J. Yamada and S. Nakatsuji, J. Mater. Chem., 2008, 18, 3433.

4 S. Castellanos, F. López-Calahorra, E. Brillas, L. Juliá and D. Velasco, Angew. Chem., Int. Ed., 2009, 48, 6516.

5 (a) C. Piechocki, J. Simon, J.-J. André, D. Guillon, P. Petit, A. Skoulios and P. Weber, Chem. Phys. Lett., 1985, 122, 124; (b) J.J. André, M. Bernard, C. Piechocki and J. Simon, J. Phys. Chem., 1986, 90, 1327; (c) Z. Belarbi, C. Sirlin, J. Simon and J.-J. André, J. Phys. Chem., 1989, 93, 8105.

6 A. G. Gürek, T. Basova, D. Luneau, C. Lebrun, E. Kol'tsov, A. K. Hassan and V. Ahsen, Inorg. Chem., 2006, 45, 1667.

7 (a) Q.-M. Wang and D. W. Bruce, Chem. Commun., 1996, 2505; (b) B. A. Gregg, M. A. Fox and A. J. Bard, J. Phys. Chem., 1990, 94, 1586; (c) K. Ohta, N. Yamaguchi and I. Yamamoto, J. Mater. Chem., 1998, 8, 2637; (d) D. Adams, F. Closs, T. Frey, D. Funhoff, D. Haarer, H. Ringsdorf, P. Schuhmacher and K. Siemensmeyer, Phys. Rev. Lett., 1993, 70, 457; (e) D. Adams, P. Schuhmacher, J. Simmerer, L. Haussling, K. Siemensmeyer, K. H. Etzbach, H. Ringsdorf and D. Haarer, Nature, 1994, 371, 141; $(f)$ L. Schmidt-Mende, A. Fechtenkotter, K. Mullen, E. Moons, R. H. Friend and J. D. Mackenzie, Science, 2001, 293, 1119. 
8 (a) F. Camerel, L. Bonardi, M. Schmutz and R. Ziessel, J. Am. Chem. Soc., 2006, 128, 4548; (b) F. Camerel, R. Ziessel, B. Donnio, C. Bourgogne, D. Guillon, M. Schmutz, C. Iacovita and J.P. Bucher, Angew. Chem., Int. Ed., 2007, 46, 2659.

9 (a) W. H. Binder, L. Petraru, T. Roth, P. W. Groh, V. Palfi, S. Keki and B. Ivan, Adv. Funct. Mater., 2007, 17, 1317; (b) M. Maeda, C. S. Kuroda, T. Shimura, M. Tada, M. Abe, S. Yamamuro, K. Sumiyama and H. Handa, J. Appl. Phys., 2006, 99, 08H103; (c) S.-K. Ahn, R. M. Kasi, S.-C. Kim, N. Sharma and Y. Yuxiang, Soft Matter, 2008, 4, 1151.

10 (a) A. H. Maki, N. Edelstein, A. Davison and R. H. Holm, J. Am. Chem. Soc., 1964, 86, 4580; (b) R. D. Schmitt and A. H. Maki, J. Am. Chem. Soc., 1968, 90, 2288; (c) B. S. Lim, D. V. Formitchev and R. H. Holm, Inorg. Chem., 2001, 40, 4257.

11 (a) A. Rosa, G. Ricciardi and E. J. Barerends, Inorg. Chem., 1998, 37, 1368; (b) M. C. Aragoni, M. Arca, F. Demartin, F. A. Devillanova, A. Garau, F. Isaia, F. Lejl, V. Lippolis and G. Verani, J. Am. Chem. Soc., 1999, 121, 7098 .

12 (a) A. M. Giroud, A. Nazzal and U. T. Mueller-Westerhoff, Mol. Cryst. Liq. Cryst., 1980, 56, 225; (b) U. T. Mueller-Westerhoff, A. Nazzal, R. J. Cox and A. M. Giroud, Mol. Cryst. Liq. Cryst., 1980, 56, 249; (c) A. M. Giroud and U. T. Mueller-Westerhoff, Mol. Cryst. Liq. Cryst., 1977, 41, 11.

13 (a) H. Horie, A. Takagi, H. Hasebe, T. Ozawa and K. Ohta, J. Mater. Chem., 2001, 11, 1063; (b) K. Ohta, Y. Inagaki-Oka, H. Hasebe and I. Yamamoto, Polyhedron, 2000, 19, 267.

14 See for example: (a) J. M. Tunney, A. J. Blake, E. S. Davies, J. McMaster, C. Wilson and C. D. Garner, Polyhedron, 2006, 25, 591; (b) N. C. Schiødt, P. Sommer-Larsen, T. Bjørnholm, M. Folmer Nielsen, J. Larsen and K. Bechgaard, Inorg. Chem., 1995, 34, 3688; (c) D. Belo, H. Alves, E. B. Lopes, M. T. Duarte, V. Gama, R. T. Henriques, M. Almeida, A. Perez-Benitez, C. Rovira and J. Veciana, Chem.-Eur. J., 2001, 7, 511.

15 (a) K. Ray, T. Weyhermuller, A. Goossens, M. W. J. Craje and K. Wieghardt, Inorg. Chem., 2003, 42, 4082; (b) K. Ray, T. Weyhermulller, F. Neese and K. Wieghardt, Inorg. Chem., 2005, 44, 5345.

16 S. Kokatam, K. Ray, J. Pap, E. Bill, W. E. Geiger, R. J. LeSuer, P. H. Rieger, T. Weyhermuller, F. Neese and K. Wieghardt, Inorg. Chem., 2007, 46, 1100.
17 A. J. Schultz, H. H. Wang, L. C. Soderholm, T. L. Sifter, J. M. Williams, K. Bechgaard and M.-H. Whangbo, Inorg. Chem., 1987, 26, 3757.

18 (a) G. Rindorf, N. Thorup, T. Bjørnholm and K. Bechgaard, Acta Crystallogr., Sect. C: Cryst. Struct. Commun., 1990, 46, 1437; (b) N. C. Schiødt, T. Bjørnholm, K. Bechgaard, J. J. Neumeier, C. Allgeier, C. S. Jacobsen and N. Thorup, Phys. Rev. B: Condens. Matter, 1996, 53, 1773.

19 O. J. Dautel, M. Fourmigué, E. Canadell and P. Auban-Senzier, $A d v$. Funct. Mater., 2002, 12, 693.

20 N. Tenn, N. Bellec, O. Jeannin, L. Piekara-Sady, P. Auban-Senzier, J. Iniguez, E. Canadell and D. Lorcy, J. Am. Chem. Soc., 2009, 131, 16961.

21 R. Perochon, C. Poriel, O. Jeannin, L. Piekara-Sady and M. Fourmigué, Eur. J. Inorg. Chem., 2009, 5413.

22 R. Perochon, L. Piekara-Sady, W. Jurga, R. Clérac and M. Fourmigué, Dalton Trans., 2009, 3052.

23 (a) G. N. Schrauzer and V. P. Mayweg, J. Am. Chem. Soc., 1965, 87, 1483; (b) M. C. Aragoni, M. Arca, T. Cassano, F. A. Devillanova, F. Isaia, V. Lippolis, A. Mancini, L. Pala, A. M. Z. Slawin and J. D. Wollins, Inorg. Chem., 2005, 44, 9610.

24 (a) K. H. Drexhage and U. T. Mueller-Westerhoff, IEEE J. Quantum Electron., 1972, 8, 759; (b) U. T. Mueller-Westerhoff and B. Vance, Comprehensive Coordination Chemistry, Ed.: Sir G. Wilkinson F R S, Pergamon Press, Oxford, 1987, ch. 16.5, p. 595; (c) K. L. Marshall, S. Schudel and I. A. Lippa, Proc. SPIE. Int. Soc. Opt. Eng., 2004, 52B, 201.

25 G. C. Papavassiliou, G. C. Anyfantis, C. P. Raptopoulou, V. Psycharis, N. Ioannidis, V. Petrouleas and P. Paraskevopoulou, Polyhedron, 2009, 28, 3368.

26 F. Camerel, G. Ulrich, J. Barbera and R. Ziessel, Chem.-Eur. J., 2007, 13, 2189.

27 J. C. Bonner and M. E. Fisher, Phys. Rev., 1964, 135, A640.

28 (a) O. Kahn, Molecular Magnetism, VCH, 1993, Ch. 11; (b) W. Estes, D. P. Gavel, W. E. Hatfield and D. Hogdson, Inorg. Chem., 1978, 17, 1415.

29 (a) S. Suarez, O. Mamula, D. Imbert, C. Piguet and J.-C. G. Bünzli, Chem. Commun., 2003, 1226; (b) S. Suarez, D. Imbert, F. Gumy, C. Piguet and J.-C. G. Bünzli, Chem. Mater., 2004, 16, 3257; (c) E. Terazzi, S. Torelli, G. Bernardinelli, J.-P. Rivera, J.-M. Bénech, C. Bourgogne, B. Donnio, D. Guillon, D. Imbert, J.-C. G. Bünzli, A. Pinto, D. Jeannerat and C. Piguet, J. Am. Chem. Soc., 2005, 127, 888. 